\title{
Analysis of Wind Turbine Driven PM Generator with Power Converters
}

\author{
R. Bharanikumar ${ }^{1}$ and A. Nirmal Kumar ${ }^{2}$
}

\begin{abstract}
A Wind Generator System that employs a boost chopper and a permanent magnet synchronous generator is studied. By replacing the main circuit of generator and boost chopper with the equivalent circuit, the power and DC output voltage are obtained as a function of duty ratio of the boost chopper and generator rotational frequency. Maximum power from the generator characterized by the load and optimum duty ratio is theoretically determined. Results of MATLAB/ SIMULINK simulation are presented.
\end{abstract}

Index Terms - PMG, Rectifier, Chopper, Inverter, Wind Turbine

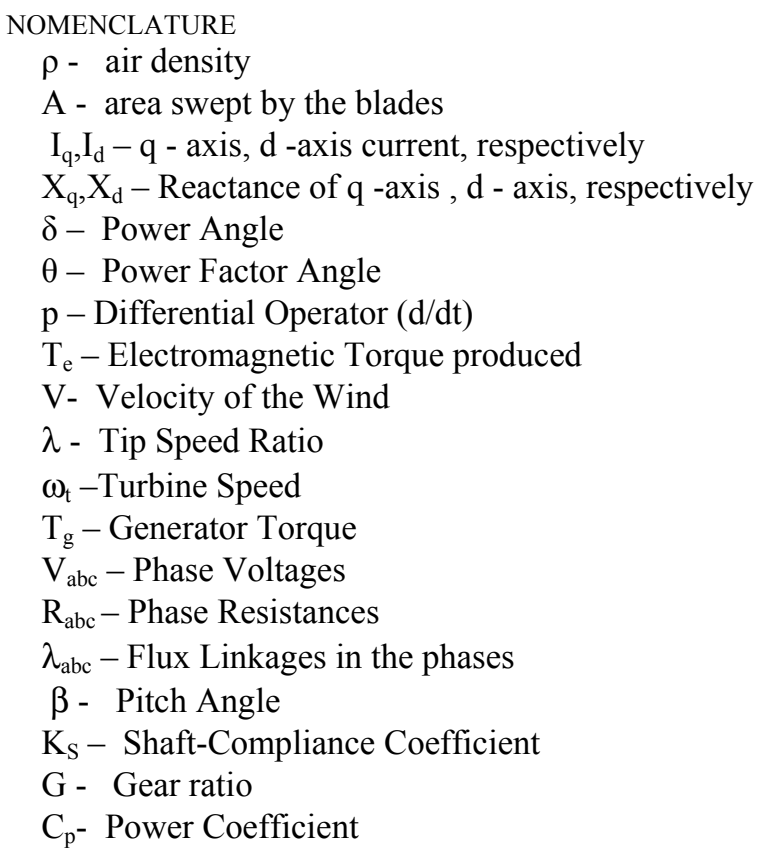

\section{INTRODUCTION}

Consumption of energy based on fossil fuels is considered to be the major factor for global warming and environment degradation. The utilization of naturally occurring renewable energy sources as an alternative energy supply has been assuming more importance of less Power generation utilizing solar rays geothermal energy, wind force and wave force has became a reality.

Research on performance improvement of and cost reduction in such non-conventional energy conversion

R. Bharanikumar is with the Department of Electrical Engineering, Bannari Amman Institute of Technology, Sathyamangalam, India (Corresponding author to provide e-mail: bharani_rbk@rediffmail.com).

A. Nirmal Kumar is with the Department of Electrical Engineering, Bannari Amman Institute of Technology, Sathyamangalam, India. systems is being accorded the highest priority [7]. Wind power generation has a strong connection to rotating machinery and hence its practical application is most promising. Wind generator control methods have already been proposed to efficiently utilize the wind power which is prone to fluctuation every moment. The induction type machine has the advantages of robustness, low cost and maintenance-free operation. However, they have the drawbacks of low power factor and need for an $\mathrm{AC}$ excitation source. Permanent magnet generator is chosen so as to eliminate the drawbacks of induction generator. Boost chopper circuit with a single switching device is the choice for power control that provides an improved efficiency [8].

For analysis of the above wind generator system, the generator and boost chopper are represented by their equivalent circuits. Performance characteristics such as generated output power and DC output voltage are expressed as functions of the duty cycle of chopper and shaft speed of generator. The power generated varies with load with the peak occurring at certain load. Therefore, the optimum duty cycle for maximum power can be deduced by differentiating the output power with respect to duty cycle. The validity of the technique for arriving at the maximum power is confirmed in the simulation study. In the present analysis, the value of each part is calculated on the basis of the rotational speed observed by the rotation sensor. Considerations of the characteristics of the wind mill are not necessary, because the torque is a function of the generator speed and characteristics of the wind mill are reflected in the rotational speed [7].

\section{COMPONENTS OF Wind ELECTRIC SYSTEMS}

The basic components of a wind electric system analyzed herein are shown in Fig 1. A step-up gear box and a suitable coupling connect the wind turbine to the Permanent Magnet Synchronous Generator (PMSG). The generated power of continuously varying frequency is fed to local load through suitable power converters, to ensure constant voltage and constant frequency [4].

Since the wind power fluctuates with wind velocity, the generator output voltage and frequency vary continuously. The varying $\mathrm{AC}$ voltage is rectified into $\mathrm{DC}$ in a diode bridge and the dc voltage is then regulated to obtain constant voltage by controlling the duty ratio of a DC/DC boost converter. The $\mathrm{DC}$ voltage is inverted to get the desired AC voltage and frequency employing a PWM inverter [4]. The duty ratio, $\delta$ controls the Boost chopper output voltage. 


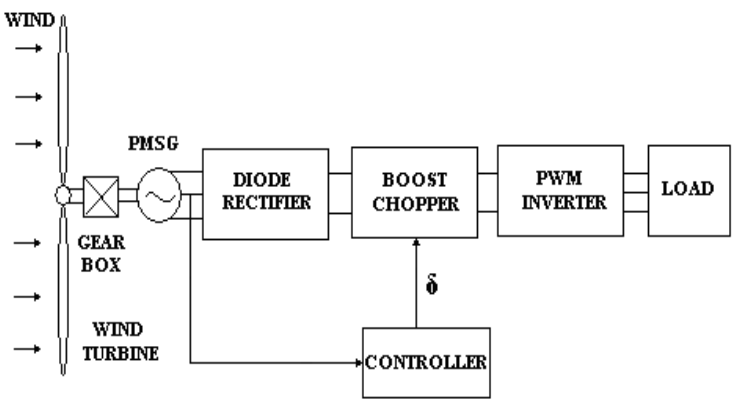

Fig 1. Block diagram of Wind Electric Generator system

\section{THEORETICAL ANALYSIS}

\section{A. Wind Turbine Model}

There are two types of wind turbines namely vertical axis and horizontal axis types. Horizontal axis wind turbines are preferred due to the advantages of ease in design and lesser cost particularly for higher power ratings [3].

The power captured by the wind turbine is obtained as

$\mathrm{P}=\frac{1}{2} \pi \rho \mathrm{R}^{3} \mathrm{~V}^{2} \mathrm{C}_{\mathrm{p}}$

where the power coefficient $\mathrm{C}_{\mathrm{p}}$ is a nonlinear function of wind velocity and blade pitch angle and is highly dependent on the constructive features and characteristics of the turbine. It is represented as a function of the tip speed ratio $\lambda$ given by

$\lambda=\frac{\mathrm{R} \omega_{\mathrm{t}}}{\mathrm{V}}$

It is important to note that the aerodynamic efficiency is maximum at the optimum tip speed ratio. The torque value obtained by dividing the turbine power by turbine speed, is formed obtained as follows:

$\mathrm{T}_{\mathrm{t}}\left(\mathrm{V}, \omega_{\mathrm{t}}\right)=\frac{1}{2} \pi \rho \mathrm{R}^{2} \mathrm{C}_{\mathrm{t}}(\lambda) \mathrm{V}^{3}$

where $C_{t}(\lambda)$ is the torque co-efficient of the turbine, given by

$C_{t}(\lambda)=\frac{C_{p}(\lambda)}{\lambda}$

The power co-efficient $C_{p}$ is given by

$\mathrm{C}_{\mathrm{p}}(\lambda)=\left(\frac{116}{\lambda 1}-(0.4 * \beta)-5\right) 0.5 \mathrm{e}^{\frac{-165}{\lambda 1}}$

Where

$\lambda_{1}=\frac{1}{\left(\frac{1}{(\lambda+0.089 \beta)}-\frac{0.035}{\beta^{3}+1}\right)}$

\section{B. Permanent Magnet Generator Model}

Permanent Magnet Generator provides an optimal solution for varying-speed wind turbines, of gearless or single-stage gear configuration[5]. This eliminates the need for separate base frames, gearboxes, couplings, shaft lines, and pre-assembly of the nacelle. The output of the generator can be fed to the power grid directly. A high level of overall efficiency can be achieved, while keeping the mechanical structure of the turbine simple [5].

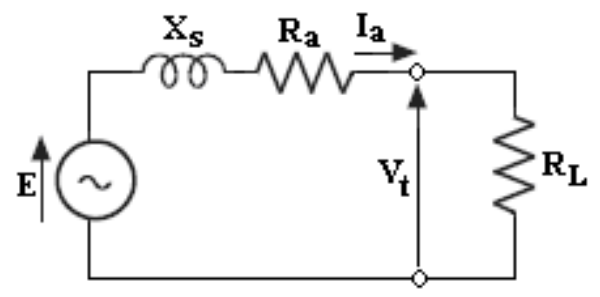

Fig 2. Equivalent circuit PM Generator for one phase

Generated emf / phase ,

$$
\begin{aligned}
& \mathrm{E}=\mathrm{V}_{\mathrm{t}}+\mathrm{I}_{\mathrm{a}}\left(\mathrm{R}_{\mathrm{a}}+\mathrm{j} \mathrm{X}_{\mathrm{s}}\right)=\mathrm{V}_{\mathrm{t}}+\mathrm{I}_{\mathrm{a}} \mathrm{Z}_{\mathrm{s}} \\
& \text { where } \quad \mathrm{Z}_{\mathrm{s}}=\sqrt{\mathrm{Ra}^{2}+\mathrm{Xs}^{2}}
\end{aligned}
$$

The rotor reference frames of the voltages are obtained as The rotor reference frames of the voltages are

$$
\begin{aligned}
& V_{\mathrm{q}}=\left(\mathrm{R}_{\mathrm{S}}+\mathrm{L}_{\mathrm{q}} \mathrm{p}\right) \mathrm{I}_{\mathrm{q}}-\omega_{\mathrm{r}} \mathrm{L}_{\mathrm{d}} \mathrm{I}_{\mathrm{d}}+\omega_{\mathrm{r}} \lambda_{\mathrm{m}} \\
& \mathrm{V}_{\mathrm{d}}=\left(\mathrm{R}_{\mathrm{S}}+\mathrm{L}_{\mathrm{d}} \mathrm{p}\right) \mathrm{I}_{\mathrm{d}}+\omega_{\mathrm{r}} \mathrm{L}_{\mathrm{q}} \mathrm{I}_{\mathrm{q}}
\end{aligned}
$$

The expression for the electromagnetic (EM) torque in the rotor is given by

$\mathrm{T}_{\mathrm{e}}=\left(\frac{3}{2}\right)\left(\frac{\mathrm{P}_{\mathrm{n}}}{2}\right)\left[\left(\mathrm{L}_{\mathrm{d}}-\mathrm{L}_{\mathrm{q}}\right) \mathrm{I}_{\mathrm{q}} \mathrm{I}_{\mathrm{d}}-\lambda_{\mathrm{m}} \mathrm{I}_{\mathrm{q}}\right]$

The relationship between the angular frequency of the stator voltage $\left(\omega_{\mathrm{r}}\right)$ and the mechanical angular velocity of the rotor $\left(\omega_{\mathrm{m}}\right)$ is obtained as follows:

$\omega_{\mathrm{r}}=\frac{\mathrm{P}_{\mathrm{n}}}{2} \omega_{\mathrm{m}} \mathrm{G}$

$p \omega_{\mathrm{r}}=\frac{\mathrm{P}_{\mathrm{n}}}{2 \mathrm{~J}_{\mathrm{g}}}\left(\mathrm{T}_{\mathrm{m}}-\mathrm{T}_{\mathrm{e}}\right)$

$\mathrm{p} \theta=\omega_{\mathrm{r}}$

Torque developed by the turbine $T_{t}$ released to the input to the generator $T_{m}$ is expressed as

$\mathrm{T}_{\mathrm{m}}=\frac{\mathrm{T}_{\mathrm{t}}}{\mathrm{G}}$

\section{Rectifier Model}

A three-phase diode bridge rectifier converts the $\mathrm{AC}$ generated output voltage, which will be varying in magnitude and also in frequency, into DC[9].

The average output voltage of the three phase diode rectifier is obtained as follows:

$\mathrm{V}_{\mathrm{dc}}=\left(3 * \mathrm{~V}_{\mathrm{m}}\right) / \pi$

and the average and RMS load current are given by:

$\mathrm{I}_{\mathrm{dc}}=\mathrm{V}_{\mathrm{dc}} / \mathrm{R}_{\mathrm{L}}$
$\mathrm{I}_{\mathrm{rms}}=\mathrm{V}_{\mathrm{rms}} / \mathrm{R}_{\mathrm{L}}$ 


\section{Boost Chopper}

The conversion of rectified DC voltage to any specified DC output voltage can be carried out employing a DC-DC converter or chopper circuit[9].

The boost chopper output voltage is obtained as

$$
\begin{aligned}
& \mathrm{V}_{\mathrm{o}}=\mathrm{V}_{\mathrm{s}}\left(\mathrm{T} /\left(\mathrm{T}-\mathrm{T}_{\mathrm{on}}\right)\right) \\
& \mathrm{V}_{\mathrm{o}}=\left(\mathrm{V}_{\mathrm{s}} /(1-\delta)\right)
\end{aligned}
$$

where $\delta=$ Duty ratio of the chopper

\section{E. PWM Inverter Model}

For providing electric power to industrial applications in the form of $\mathrm{AC}$, the $\mathrm{DC}$ output of Boost Chopper is inverted in a three - phase inverter. Gating signals for PWM Inverter devices are generated employing a Sinusoidal Pulse Width Modulation Technique (SPWM), by comparing a sinusoidal reference signal with a triangular carrier wave. The frequency of reference signal $f_{r}$ determines the inverter output frequency $f_{O}$ and its peak amplitude controls the modulation index $\mathrm{M}$ and this in turn the rms output voltage, $\mathrm{V}_{\mathrm{O}}[11]$.

If $\delta_{m}$ is the width of the $m^{\text {th }}$ pulse and $p$ is the number of pulses, then the rms output voltage is obtained as:

$\mathrm{V}_{\mathrm{ac}}=\mathrm{V}_{\mathrm{in}}\left(\sum_{\mathrm{m}=1}^{2 \mathrm{pu} 1} \frac{\delta_{\mathrm{m}}}{\pi}\right)^{\frac{1}{2}}$

\section{RESUltS}

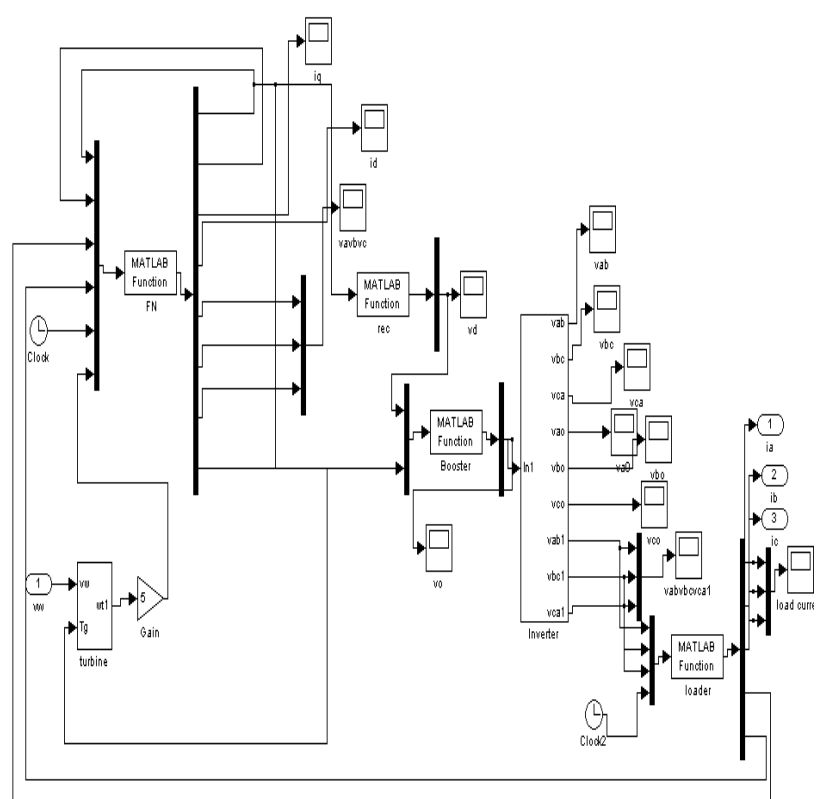

Fig 3.Simulation Model of Wind Generator System
Electric Conversion System. This model is simulated for various wind velocities, see Fig. 4-to 10

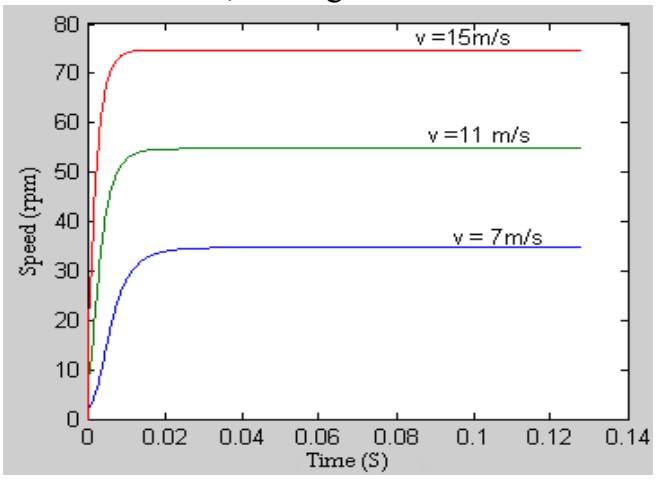

Fig 4. Wind Turbine Speed

Fig 4 shows the wind turbine speed in rpm for different values of wind velocity. Wind turbine reaches the steady state at $\mathrm{t}=3$ milliseconds at all wind velocities.

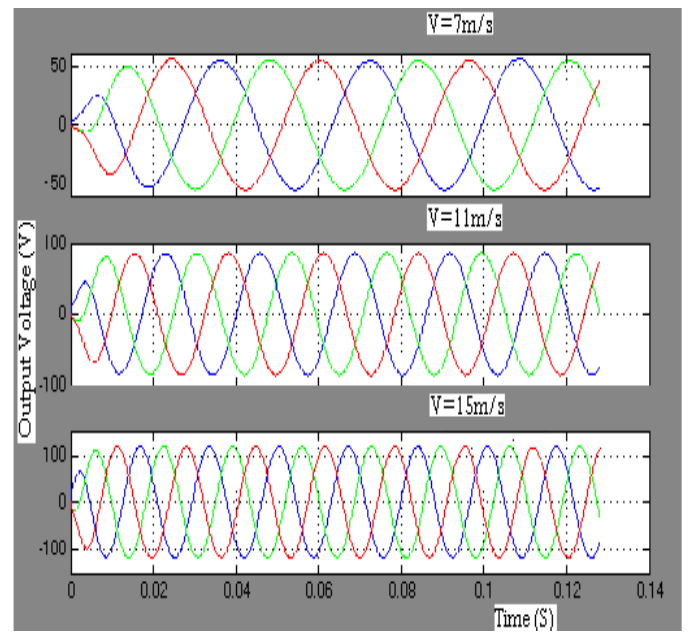

Fig 5. PMSG Output Voltage

Fig.5 shows the Permanent Magnet Generator output voltages for different values of wind velocities. The generated voltage reaches steady state at $\mathrm{t}=3$ milliseconds

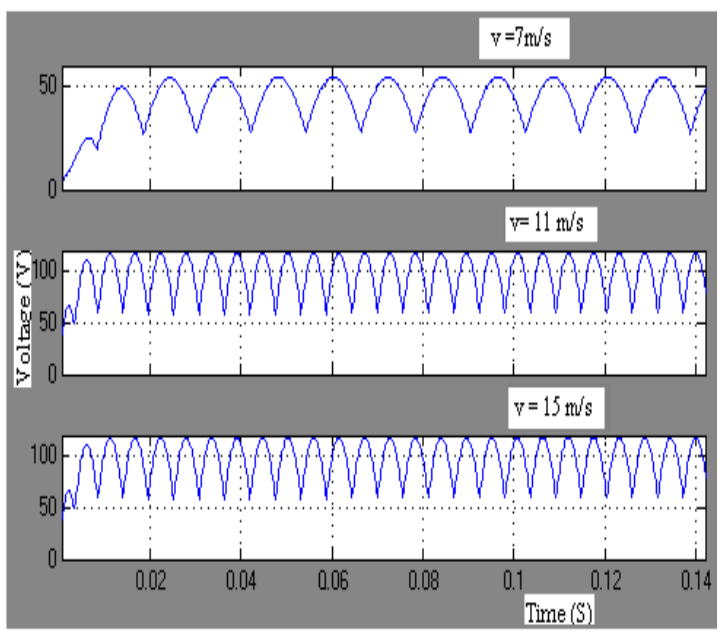

Fig 6. Rectifier Output Voltage

Fig 3. shows the overall simulation model of Wind 


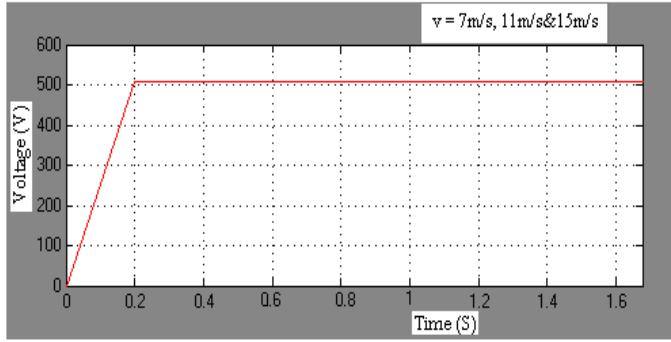

Fig 7 .Boost Chopper Output Voltage

Fig 6 shows the diode rectifier output voltage for various wind velocity. Fig 7 shows the boost chopper output voltage for different values of wind velocity. The chopper output voltage is 508volt constant. This is given to SPWM inverter.

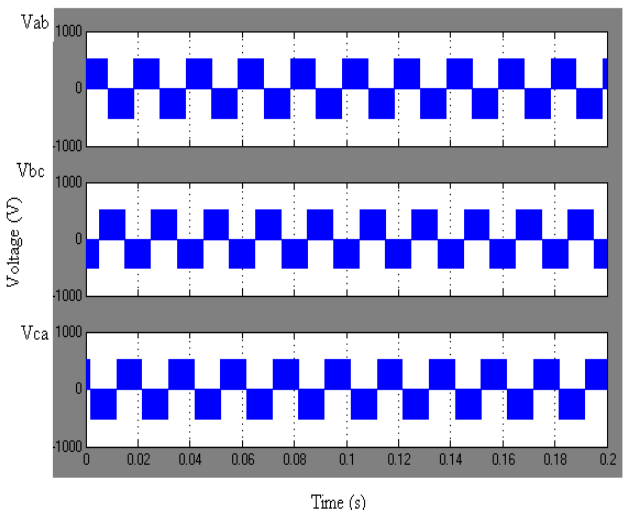

Fig 8. SPWM Inverter Output Voltage

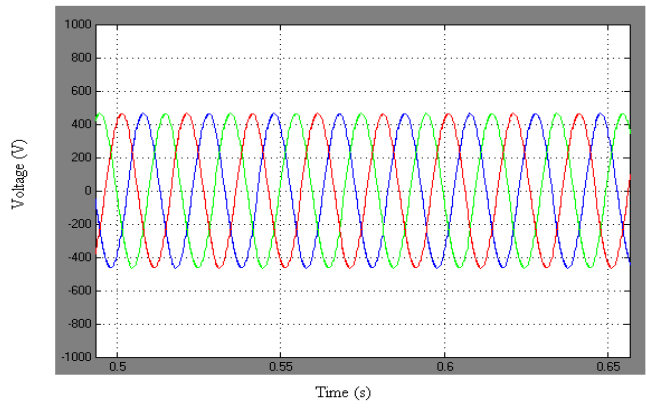

Fig 9 .Sinusoidal Output Voltage of SPWM Inverter

Fig 8 and 9 shows the inverter output voltage of 415 Volt $\mathrm{AC}$ for different values of wind velocity, this is constant ac voltage is given to load.

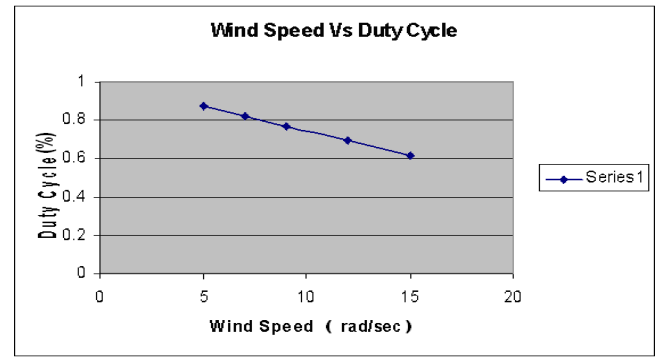

Fig 10. Wind Speed Vs Chopper Duty cycle

Fig 10. shows the Boost chopper Duty ratio for Maintain the dc voltage at desired level for various values of wind velocities

\section{CONCLUSION}

The wind turbine driven Permanent Magnet Generator is modeled using MATLAB/SIMULINK tool and analyzed for various input wind velocities. As the wind velocity varies the output voltage of PMSG also varies. The varying voltage is rectified into DC and is stepped up in a boost chopper producing a constant DC voltage irrespective of wind velocities. The constant DC voltage from the chopper is inverted in a Sinusoidal Pulse Width Modulated (SPWM) Inverter to obtain an $\mathrm{AC}$ output of constant voltage and constant frequency. Simulation study on a Wind Generated System employing MATLAB/SIMULINK model is the core coverage in this paper.

\section{REFERENCES}

[1] Monica Chinchilla, Santiago Arnaltes,Juan Carlos Burgos," Control of permanent-magnet generators applied to variable-speed windenergy systems connected to the grid", IEEE Transactions on Energy Conversion, vol 21, no 1, March 2006, pp.130-135

[2] P. Anandavel, K. Rajambal and C. Chellamuthu: "Power optimization in a grid-connected wind energy conversion system",IEEE Conf. PEDS 2005, pp.1617-1621.

[3] Kelvin Tan,Syed Islam:" Optimum control strategies in energy conversion of pmsg wind turbine system without mechanical sensors",IEEE Transactions on Energy Conversion, vol. 19, no. 2, June 2004, pp.392-399

[4] ShigeoMorimoto,Hideaki Nakayama, Masayuki Sanada, Yoji Takeda:"Sensorless output maximization control for variable-speed wind generation system using IPMSG", IEEE Transactions on Industrial Applications 2003,pp.1464-1471

[5] A.B. Raju, K.Chatterjee and B.G. Fernandes, "A Simple Power Point tracker for grid connected variable speed wind energy conversion system with reduced switch count power converters" IEEE Transactions on Power Electronics,2003. pp 456-462.

[6] Tomohiko Nakamura, Shigeo Morimoto, Masayuki Sanada, Yoji Takeda:" Optimum control of IPMSG for wind generation system", PCC-Osaka 2002, pp.1435-1440.

[7] Kenji Amei Yukichi 'Igkayasu Takahisa Ohji Masaaki Sakui:," A Maximum power control of wind generator system using a permanent magnet synchronous generator and a boost chopper circuit," PCC-Osaka 2002, pp.1477- 1452.

[8] N.Yamamura, M.Ishida, T.Hori: "A Simple wind power generating system with permanent magnet type synchronous generator", IEEEConf. PEDS'99, pp.849-854,

[9] Eduard.Muljadi,Stephen.Drouilhet,fichard.Holz,Vahan Gevorgian, "Analysis of permanent magnet generator for wind power battery charging”, IEEE Ind.Appl. 1996, Vol.1 pp.541-548, 1996.

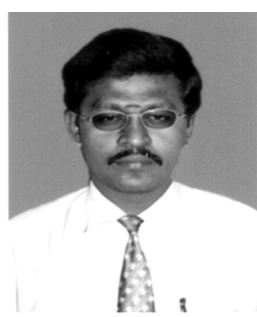

Bharanikumar.R was born in Tamilnadu, India, on May 30, 1977. He received the B.E degree in Electrical and Electronics Engineering from Bharathiyar University, in 1998. He received his M.E Power Electronics and Drives from College of Engineering Guindy Anna University in 2002. He has 9 yrs of teaching experience. Currently he is working as Asst. Professor in EEE department, Bannari Amman Institute of Technology, Sathyamangalam, TamilNadu, India. Currently he is doing research in the field of power converter for wind energy conversion system, vector controller for synchronous machine drives.

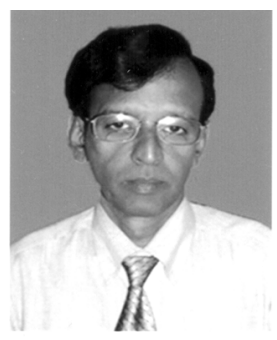

Dr.A.Nirmal Kumar was born in the year 1951. $\mathrm{He}$ completed his PG and UG in Electrical Engineering from Kerala and Calicut University respectively. He completed $\mathrm{PhD}$ in Power Electronics in the year 1992 from P.S.G. College of Technology, Coimbatore under Bharathiar University. He was with N.S.S. College of Engineering for nearly 28 years in various posts before joining Bannari Amman Institute of Technology, Sathyamangalam, TamilNadu, India in the year 2004. He is a recipient of Institution of Engineers Gold Medal in the year 1989. His current research areas include Power converters for Wind Energy Conversion System and Controller for Induction motor drives. 